\title{
Adición de Bacillus Coagulans (Lactbacillus Esporogenes) a una Mezcla en Polvo a Base de Cereales Instantáneos
}

\author{
Addition of Bacillus Coagulans (Lactbacillus Esporogenes) \\ to a Powder Mixture Based Instant Cereals
}

\section{Libreros López Martha Lucia', Jiménez Porras Marino²}

\author{
${ }^{1}$ Escuela de Ciencias Básicas Tecnología e Ingeniería, Universidad Nacional Abierta y a Distancia-UNAD, \\ mlibrerosleunadvirtual.edu.co. \\ ${ }^{2}$ Escuela de Ciencias Básicas Tecnología e Ingeniería, Universidad Nacional Abierta y a Distancia-UNAD, \\ mjimenezp @unadvirtual.edu.co
}

Recibido: 07/10/2011• Aprobado: 27/11/2011

\section{RESUMEN}

En este artículo se dan a conocer los resultados de la aplicación de un probiótico a una fórmula infantil a base de cereales instantáneos, mediante evaluación de vida útil acelerada. Este proceso se lleva a cabo a nivel de laboratorio, con base en la técnica de ensayo/error.

La cepa del probiótico seleccionado, lactobacilluis (Bacillus coagulans), debe cumplir con las siguientes características: ser de origen humano, sobrevivir durante el tránsito gástrico, tolerar sales biliares y adherirse al tejido epitelial intestinal. Desde el punto de vista tecnológico, el probiótico debe: ser tolerante al oxígeno y a los ácidos, tener habilidad para crecer en leche y para metabolizar probióticos y no afectar las características sensoriales del producto.

El probiótico debe ajustarse a los requerimientos técnicos y de producción y ser resistente a condiciones externas adversas que pudiesen modificar su composición o vida.

El proceso de incorporación de probióticos a la mezcla de cereal infantil se realiza mediante una base de cálculo teórico. Si se utiliza la dosis recomendada, se garantiza la presencia del Bacillus coagulans durante la vida útil acelerada.

Palabras clave: bacillus coagulans, cereales instantáneos, lactobacilluis, probiótico, vida útil acelerada 


\section{Abstract}

This paper discloses the results of the application of a probiotic infant formula based instant cereals through accelerated life assessment. This process is carried out at laboratory level, based on the assay technique / error.

The selected strain of probiotic, Lactobacilluis (Bacillus coagulans), must comply with the following characteristics: be of human origin, survival during gastric transit, bile salts tolerate and adhere to intestinal epithelial tissue. From the technological point of view, the probiotic must: be tolerant to oxygen and acids, have the ability to grow in milk and probiotics to metabolize and not affect the sensory characteristics of the product.

The probiotic must meet the technical and production requirements and be resistant to adverse external conditions that may alter its composition or life.

The process of incorporating probiotics to infant cereal mixture is performed by a theoretical calculation based. If the recommended dose is used, the presence of bacillus coagulans is ensured during the accelerated life.

Keywords: accelerated lifetime, bacillus coagulans, instant cereals, lactobacilluis, probiotic

\section{INTRODUCCIÓN}

Los probióticos son microorganismos vivos que proporcionan efectos benéficos sobre la flora intestinal. Se les atribuye papeles importantes en las funciones inmunitarias, digestivas y respiratorias, así como en el equilibrio microbiano intestinal; ayudan, también a reforzar el sistema inmunológico y tienen efectos positivos en la salud [1].

Se experimentó la viabilidad de una cepa probiótica utilizando como vehículo un cereal infantil, a la cual, con la adición de los microorganismos probióticos, se le realizó la caracterización correspondiente con respecto a aspectos sensoriales y fisicoquímicos $(\mathrm{pH})$; así mismo se realizó la evaluación microbiológica del probiótico Bacillus coagulans en todos los tiempos de muestreo.

El estudio de estabilidad acelerada (envejecimiento acelerado a corto plazo) es un proceso investigativo diseñado con el fin de incrementar la velocidad de descomposición física y/o química de un producto, bajo condiciones ambientales de almacenamiento extremas, para determinar los parámetros cinéticos de los procesos de descomposición y/o predecir tentativamente la vida útil del producto en condiciones de almacenamiento.

\section{ManteCedentes}

\section{A. Alimentos Funcionales}

En la última década, los conceptos básicos de nutrición han cambiado; hasta ahora, la idea tradicional de una "dieta adecuada" tenía que ver únicamente con el aporte de nutrientes suficientes para asegurar la supervivencia de un individuo, satisfacer sus necesidades metabólicas y complacer su sensación de hambre. En la actualidad, el énfasis se acentúa en la potencialidad de los alimentos para la promoción de la salud, mejora del bienestar y reducción del riesgo de enfermedades. 
Así, el concepto de nutrición adecuada tiende a sustituirse por el de nutrición óptima, en cuyo ámbito aparecen los alimentos funcionales, denominación no muy acertada, pues a juicio de [2] todos los alimentos y sus componentes tienen una función.

Un alimento puede considerarse funcional, si se demuestra suficientemente que afecta de forma beneficiosa (más allá de proporcionar una nutrición adecuada desde el punto de vista tradicional) a una o varias funciones relevantes del organismo, de tal manera que proporciona un mejor estado de salud y bienestar y/o reduce el riesgo de padecer alguna enfermedad [3].

En diversas investigaciones, se ha visto que la adición de probióticos a los alimentos, provoca beneficios en la salud, entre otros, mejorr las funciones gastrointestinales, fortalece el sistema inmunológico y disminuye el riesgo del cáncer de colon [1], [4].

\section{B. Probióticos}

La Organización Mundial de la Salud (OMS) define los probióticos como "microorganismos vivos que cuando se administran en cantidades adecuadas, confieren un beneficio de salud en el huésped." Los tipos más comunes de estas bacterias beneficiosas son los lactobacilos y las bifidobacterias [5].

La palabra probiótico significa en pro de la vida. Son cultivos activos (tales como las bacterias lácticas y las sustancias) que contribuyen al equilibrio microbiano intestinal, para restituir la población del medio interno y proteger la integridad intestinal, debido a que son capaces de sobrevivir la digestión llegando vivas al colon [1], [6].

Los probióticos proporcionan muchos beneficio, sobre la flora intestinal y las funciones inmunitarias; también intervienen en la mejora de las funciones respiratorias y en el balance microbiológico. Es decir, desempeñan un papel importante en la prevención de enfermedades, por lo que alimentos adicionados con estos probióticos deben formar parte de la dieta diaria de personas sanas. Se ha comprobado que los probióticos contribuyen a disminuir la concentración de sustancias potencialmente cancerígenas, del intestino [7], [8].

\section{Lactobacilos sporogenes (B. coagulans)}

Formalmente conocido como Lactobacilos sporo-genes es un probiótico que sobrevive a temperatura ambiente y de eficacia clínicamente documentada, es decir, evaluada a partir de modelos experimentales medibles y reproducibles. Aislado por primera vez de la malta verde, las colonias de L. sporogenes en su forma esporulada sobreviven y proliferan en el tracto gastrointestinal.

En estudios en vivo se han revelado propiedades probióticas del Bacillus coagulans, tales como esporas resistentes al entorno adverso, capacidad de adherencia a la mucosa intestinal, actividad inhibidora contra las bacterias dañinas y resistencia a las duras condiciones de los procesos de fabricación.

En los seres humanos, una preparación de Bacillus coagulans alivia los síntomas clínicos de una variedad de enfermedades crónicas, incluyendo enteritis catarral aguda, diarrea, estreñimiento, fermentación intestinal anormal, infantum, la dispepsia, la diarrea neonatal, intolerancia a la lactosa, vaginitis no específica y las infecciones del tracto urinario.

1) Bacillus coagulans: bacteria's Gram-positivas. Es el único microorganismo probiótico formadr de esporas, que produce una estructura no reproductiva temporal, la cual consiste de toda la información hereditaria, envuelta por un revestimiento exterior resistente. Las esporas pueden sobrevivir sin nutrientes y son extremadamente resistentes a los factores adversos, como la radiación ultravioleta, la desecación, la temperatura alta, la congelación y los productos químicos. 


\section{Cereal Infantil:}

Los cereales han sido utilizados como vehículos en el desarrollo y producción de alimentos funcionales. Los aportes que suministran en proteína, carbohidratos, vitaminas y minerales son una alternativa más para emplearse como complementos en la alimentación de los niños, a partir de los seis meses de edad.

La administración de una dieta complementaria, estimula la función gastrointestinal y favorece el establecimiento de buenos hábitos alimenticios. Por otro lado, los cereales se recomiendan, por lo general, como comienzo de una dieta complementaria ya que presentan un elevado contenido de energía ( $80 \mathrm{kcal} / 100 \mathrm{~g}$ ) [9]. En general, los alimentos infantiles a base de cereales están elaborados con arroz o maíz. Se sabe que los cereales son pobres en aminoácidos esenciales como triptófano y lisina, por lo que para mejorar su valor nutricional, se combinan normalmente con leche [10].

Los cereales infantiles empleados en este estudio, están elaborados a base de cereales instantáneos, como harina de arroz, maíz y avena $y$ han sido enriquecidos con vitaminas y minerales, a fin de cubrir buena parte de las necesidades diarias de alimentación, recomendadas durante la infancia.

\section{Desarrollo de la Fórmula INFANTIL CON Adición de Probióticos}

Se usaron diferentes métodos para la determinación de la calidad de la materia prima:

\section{A. Análisis de humedad}

Se utilizó medidor de humedad. Este parámetro es de gran importancia en la conservación del cereal infantil. en la realización del estudio de vida útil. La humedad no debe ser mayor a $10 \%$ debido a que aumenta el riesgo de contaminación de microorganismos.

\section{B. Análisis de granulometría}

Determina el tamaño de la partícula del cereal infantil. Se utilizaron mallas de 30-60-80, con equivalencia de 30 (600 microns)-60 (250 microns)-80 (180 microns) y base (recibidor). Se determinó el porcentaje en peso retenido en cada malla o tamiz.

\section{Análisis fisicoquímico cereal infantil final}

Mediante el análisis proximal del cereal infantil se determinaron los parámetros de proteína, grasa total, cenizas, carbohidratos, fibra y calorías en 100 gramos de producto.

Mediante prueba de ensayo-error a nivel de laboratorio se realizaron 10 formulaciones tomando como base la harina de arroz por considerarse un cereal no alérgeno y de fácil digestibilidad, seguido por la avena y el maíz.

De las formulaciones realizadas mediante paneles de catación y de acuerdo con los resultados obtenidos en aceptabilidad de sabor y apariencia, se logró determinar la formulación final y se procedió a realizar la adición del probiótico.

En la adición de vitaminas y minerales se realizaron los cálculos, de acuerdo con la resolución 333 del 2011 en la que se especifican las recomendaciones diarias de calorías y nutrientes, con base en los parámetros más recomendados para la población infantil.

Para la adición del probiótico, se tuvo en cuenta la ficha técnica, y se analizó la concentración de microorganismos, para así determinar la dosis adecuada, con el fin de que cada gramo del cereal infantil contenga $106 \mathrm{UFC/g}$. Tomando como base de cálculo 15 billones de microorganismos de probióticos, se realizó un cálculo teórico de adición de 0.013 \% para garantizar la viabilidad del probiótico, durante la vida útil del alimento.

A las formulaciones realizadas se les aplicó una serie de pruebas como son, el análisis microbiológico, la determinación del PH y el análisis organoléptico o sensorial. 
TABLA I

Análisis de Humedad de la Materia Prima

\begin{tabular}{|l|c|}
\multicolumn{2}{|c|}{$\begin{array}{c}\text { Análisis de humedad de la materia } \\
\text { prima y producto final }\end{array}$} \\
\hline \multicolumn{1}{|c|}{ Materia prima } & Porcentaje \\
\hline Harina de arroz instantánea & $6.86 \%$ \\
\hline Harina de maíz instantánea & $5.45 \%$ \\
\hline Harina de avena instantánea & $4.7 \%$ \\
\hline Cereal infantil & $4.33 \%$ \\
\hline
\end{tabular}

De acuerdo con los resultados arrojados de la materia prima y cereal infantil, se puede observar que los valores obtenidos son menores a $10 \%$ en humedad [9]. Esta humedad determina la calidad y conservación de las materias primas y del producto final, debido a que evita la proliferación de microorganismos.

\section{Porcentaje de retención de partícula}

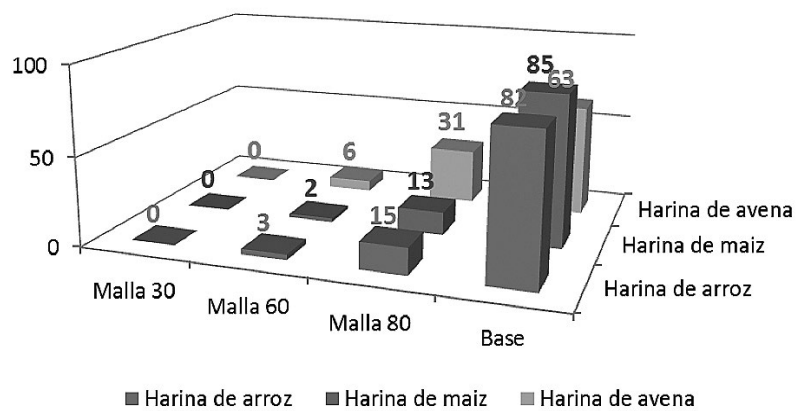

Fig. 1 Retención de particular

Los resultados obtenidos se reportan teniendo en cuenta lo retenido en cada tamiz. El tamaño de la partícula es un parámetro importante en la calidad del producto final y determina la textura y dispersión del producto una vez preparado, debido a que la estructura granular del almidón en su proceso de cocción alcanza su grado de gelatinización haciendo que la partícula, una vez disuelta, aumente la solubilidad en agua, de la fracción amilácea, provocando cambios en las propiedades reológicas.

\section{Composición porcentual de formulaciones mediante ensayo-error}

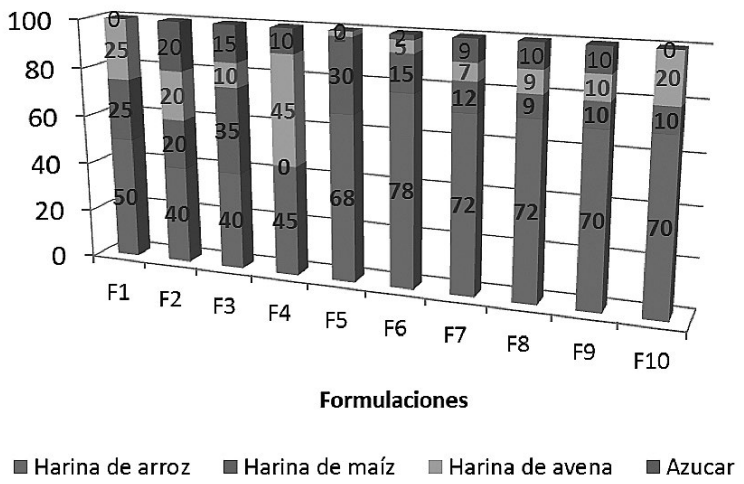

Fig. 2 Composición porcentual de formulaciones

\section{Resultados obtenidos}

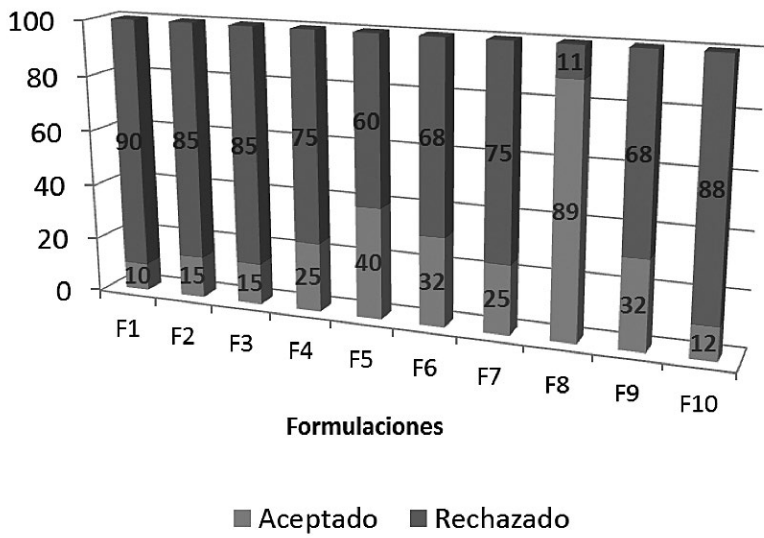

Fig. 3 Resultados obtenidos prueba aceptación

Al comparar los resultados obtenidos, la formulación de mayor aceptabilidad fue la 8, con un porcentaje de aceptabilidad del $89 \%$; las demás formulaciones se descartan por tener un porcentaje inferior en aceptación.

Estos resultados están basados en datos obtenidos por preferencia en sabor, olor y textura de las formulaciones diseñadas.

De acuerdo con estos resultados se procede a realizar la adición del probiótico al cereal infantil seleccionado. 


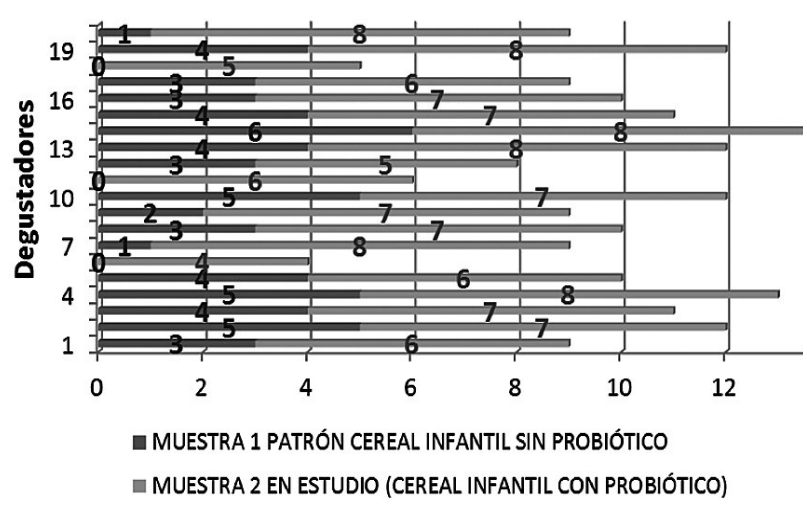

Fig. 4 Resultados obtenidos de nivel de agrado

Los resultados de análisis de agrado de aceptación del alimento, referente al cereal, son:

\section{A. Olor o aroma}

Con la adición del probiótico (bacillus coagulans) al cereal infantil, no se encontró, en los paneles realizados, diferencia en el olor, lo que indica una buena aceptación del mismo.

\section{B. Sabor}

El sabor que obtuvo más puntaje y por lo tanto el más aceptado por los catadores fue el del cereal infantil con adición del probiótico; el cereal infantil, como patrón de referencia, no muestra diferencias significativas en la aceptación de su sabor.

\section{Viscosidad}

No se encontraron diferencias significativas entre las muestras $\mathrm{A}$ y $\mathrm{B}$ en relación con la aceptación del atributo sensorial de viscosidad. Los cultivos probióticos no tuvieron gran impacto en este atributo, de acuerdo con el panel sensorial realizado.

Ninguna de las muestras presentó alteración de las características organolépticas: aspecto, color ni olor durante el tiempo de seguimiento [10], [11].

\section{CONCLUSIONES}

Teniendo en cuenta la estabilidad de la formulación, tanto desde el punto de vista sensorial como microbiológico, se determina que el tiempo de vida útil del cereal infantil con adición de probióticos, es de 12 meses a temperatura ambiente $\left(25^{\circ} \mathrm{C} \pm 2^{\circ} \mathrm{C}\right.$ HR $60 \% \pm 5 \%$ ) (Como resultado de la proyección del estudio de vida útil acelerada) siempre y cuando el producto permanezca en su empaque original, sellado herméticamente y conservando la misma calidad del material utilizado en el estudio.

El producto durante el estudio acelerado, presentó un comportamiento estable a los 50 días; se observó que cumple con las especificaciones de calidad establecidas y que los microorganismos evaluados se mantuvieron durante el tiempo de estudio.

Las muestras analizadas presentaron un alto nivel de aceptación para todos los atributos evaluados. La adición del probiótico, bacillus coagulans, no generó alteración de las características organolépticas; es decir de sabor, color, olor y apariencia en general, durante el tiempo del estudio.

De acuerdo con el estudio sensorial, este nuevo producto tiene buena aceptación y buena digestibilidad en los niños; se demostró de manera tangible que ningún niño presentó síntomas perjudiciales por su consumo, o reacción contraria a la esperada. 


\section{RECONOCIMIENTO}

A la compañía Pampa Ltda. Y en su nombre al Gerente, Edgar José Polanco Moreno por permitirnos desarrollar este trabajo de Investigación \& Desarrollo porque logramos los objetivos propuestos.

Al asesor en el trabajo de grado, ingeniero Omar Eduardo Siabatto Pérez.

Al jurado: doctor Glaehter Yhon Flórez Guzmán, por sus aportes en la culminación del trabajo de grado.

A la doctora Nelly Morales Pedraza, por su apoyo y colaboración en la culminación del trabajo de grado.

Al doctor Eliuth Mercado Sánchez, Médico General y especialista en Medicina Familiar, por su concepto científico acerca del desarrollo de un producto con adición de probióticos.

\section{ReFERENCIAS}

[1] Q. A. Lozano Pérez L. A. M. C. Estudio de la viabilidad de Lactobacillus casei Shirota en una gelatina de pitaya (Stenocereus griseus).

[2] Pérez C.D.M, Adición de probióticos y prebióticos a fórmulas infantiles y su efecto sobre la biodisponibilidad mineral. (2003).

[3] S.L., Sadell, Ultra probiotics, Barcelona, (2003).

[4] C. F., Frontela S., Efecto de la adición de fitasa sobre la biodisponibilidad mineral in vitro en papillas infantiles, (2007).

[5] Sancho, J, B, Castro. E. Introducción al análisis sensorial de los alimentos. Barcelona: Edicions Universitat de Barcelona. (1999).

[6] Hernández, E. Evaluación sensorial. Universidad nacional abierta y a distancia - Unad.(2006).

[7] Artículo organización de las naciones unidas para la agricultura y la alimentación Roma, Probióticos en los alimentos: Propiedades saludables y nutricionales y directrices para la evaluación. (2006).

[8] De Roos NM, Katan MB. Am J ClinNutr, Effects of probiotic bacteria on diarrhea, lipidmetabolism, and carcinogenesis (1998 Y 1998).

[9] Payne DC, Vinje J, Szilagyi PG, Edwards KM, Staat MA, Weinberg GA, et al. Norovirus and medically attended gastroenteritis in U.S. children. N Engl J Med 2013; 368: 1121-1130.

[10] Liu L, Johnson HL, Cousens S, Perin J, Scott S, Lawn JE, et al. Global, regional, and national causes of child mortality: an updated systematic analysis for 2010 with time trends since 2000. Lancet 2012; 379: 2151-2161.

[11] Norma Icontec, 2160. 